\title{
Transplante heterotópico do coração sem auxílio da circulação extracorpórea: estudo experimental em cães
}

Roberto Gomes de CARVALHO*, Antoninho KRICHENKO*, Paulo GIUBLIN*, Alexandre VARELA*, Maria João AMORIM*, Ronaldo Loures BUENO*, Edison José RIBEIRO*, Paulo Roberto BROFMAN*, Danton Rocha LOURES*

\section{RBCCV}

CARVALHO, R. G.; KRICHENKO, A.; GIUBLIN, P.; VARELA, A.; AMORIM, M. J.; BUENO, R. L.; RIBEIRO, E. J.; BROFMAN, P. R.; LOURES, D. R. - Transplante heterotópico do coração sem auxilio da circulaçāo extracorpórea: estudo experimental em câes. Rev. Bras. Cir. Cardiovas., 1(2):49-56, 1986.

RESUMO: Os autores descrevem nova técnica de transplante heterotópico do coraçăo. Foram operados 14 cáes. A via de acesso foi toracotomia lateral esquerda e foram realizadas somente duas anastomoses, năo sendo necessário o uso da circulaçăo extracorpórea. Como resultado, houve boa adaptação dos cães ao procedimento e comprovou-se a eficiência do método através do estudo hemodinâmico. Esta técnica poderá, eventualmente, ser aplicada na clínica.

DESCRITORES: transplante cardiaco, heterotópico, experimental.

\section{INTRODUÇĀO}

Um dos primeiros estudos experimentais de transplante cardiaco foi realizado por CARREL \& GUTHRIE ${ }^{7}$, em 1905. Neste trabalho, os autores faziam anastomoses da veia jugular externa e carótida do receptor com aorta, tronco pulmonar, veia cava e uma das veias pulmonares do doador (Figura 1). Bem mais tarde, MANN et alii ${ }^{16}$ anastomosavam a aorta com a carótida interna e tronco pulmonar (TP) com veia jugular.

Com o decorrer dos anos, vários autores ${ }^{10,} 18$ publicaram técnicas experimentais das mais variadas, para realização do transplante heterotópico (TH). Apesar dos bons resultados do transplante ortotópico (TO $)^{1.9}$, podemos salietar que o $\mathrm{TH}$ apresenta algumas vantagens sobre o $\mathrm{TO}^{3,5}, 6$. $\mathrm{Na}$ literatura brasileira, existe apenas um trabalho experimental sobre TH, realizado por BARBEROMARCIAL et alii ${ }^{2}$ em 1971 . Os objetivos do presente artigo são: desenvolver técnica experimental em nosso meio, demonstrar a facilidade de realização do TH e a comprovação dạ técnica através do estudo hemodinâmico.

\section{MATERIAL E MÉTODO}

No período de agosto de 1985 a janeiro de 1986 , foram operados 14 cães mestiços, adultos, pesando entre 13 e $24 \mathrm{~kg}$. Em 3 cães, foi realizado 
CARVALHO, R. G.; KRICHENKO A.; GIUBLIN, P.; VARELA, A.; AMORIM, M. J.; BUENO, R. L.; RIBEIRO, E. J.; BROFMAN, P. R.; LOURES. D. R. - Transplante heterotópico do coração sem auxilio da circulação extracórporea: estudo experimental em cães. Rev. Bras. Cir. Cardiovasc., 1(2):49-56, 1986.

estudo hemodinâmico após a volta dos batimentos cardíacos do coração transplantado.

A anestesia foi iniciada com cloridrato de quetamina, intramuscular, na dose de $5 \mathrm{mg} / \mathrm{kg} /$ peso e atropina, via venosa, na dose de $0,002 \mathrm{mg} / \mathrm{kg} /$ peso. A indução foi realizada com tionembutal sódico (3 $\mathrm{mg} / \mathrm{kg} / \mathrm{peso})$. brometo de pancurônio $(0,1 \mathrm{mg} / \mathrm{kg} /$ peso) e fentanil ( $1 \mathrm{ml} / \mathrm{kg} /$ peso), por via intravenosa. Os cães foram entubados por via endotraqueal e a ventilação, realizada com respirador de TAKAO$\mathrm{KA}^{20}$.

\section{Técnica Cirúrgica}

Cão doador (D) - A via de acesso foi toracotomia mediana transesternal. Após abertura do pericárdio, a crossa da aorta foi dissecada amplamente até a emergência do 1: ramo intercostal. As veias pulmonares do lado direito foram ligadas e seccionadas. A veia cava superior (VCS) foi dissecada amplamente e a veia ázigos foi ligada e seccionada. Uma cânula arterial ( $8 \mathrm{~F}$ ) foi introduzida no tronco branquiocefálico direito, para injetar solução cardioplégica e uma agulha de "vacuoliter" foi introduzida em outro tronco braquiocefálico, para retirada de sangue. A seguir, a VCS foi ligada e seccionada e a $\mathrm{VCl}$ foi clampeada, bem como a aorta torácica descendente, perto do 1? ramo intercostal. Imediatamente, após a ligadura dos ramos da crossa, foi injetada solução cardioplégica a $4^{\circ} \mathrm{C}$, com bomba de rolete. Pouco antes, o sangue foi coletado em um recipiente plástico, com solução anticoagulante. Após a parada cardíaca, o coração foi retirado, seccionando-se a aorta perto da pinça de clampeamento, as veias pulmonares do lado esquerdo e o tronco pulmonar (TP), logo acima da valva pulmonar. Colocado o coração em um recipiente contendo soro gelado, foi aberto o átrio direito $(A D)$ e ressecada a valva tricúspide. A seguir, foi criada uma ampla comunicação interatrial (CIA) e, então, fechados os $A D$ e VCl com fio de polipropileno n: 6-0. O TP foi suturado com fio de polipropileno n: 5-0.

Cão receptor (R) - O cão (R) foi monitorizado com derivações precordiais e traçado do ECG; a artéria femoral esquerda, coneccionada ao manômetro de mercúrio para registrar a pressão arterial média (PAm) e dissecada a veia femoral comum direita. A via de acesso foi uma toracotomia no 4 : espaço intercostal esquerdo e a hemostasia, realizada com eletrocautério. A seguir, a aorta torácica descendente foi dissecada e preparada ao nível do hilo pulmonar, bem como a veia pulmonar superior esquerda, na junção do átrio esquerdo (AE). Com clampeamento parcial da aorta do $(R)$, foi realizada anastomose com aorta do (D) com fio de polipropileno n: 4-0, em sutura contínua. Antes de soltar a pinça do clampeamento parcial, a aorta do (D) foi clampeada acima dos vasos da crossa, para retirada de ar. Através de uma sutura em belsa realizada na aurícula esquerda e heparinização na dose de $1 \mathrm{mg} / \mathrm{kg} /$ peso, foi introduzida uma câňula arterial $(8 \mathrm{~F})$ e, com um tubo de $3 / 8$ de polegada, a outra extremidade foi coneccionada na veia femoral. Após este tempo, foi liberada a pinça da aorta. Assim, para evitar distensão do coração (D), o sangue do seio coronário drenaria para o cão (R). Após esta manobra, o coração (D) voltou a bater espontaneamente, ou foi necessário, em alguns casos, realizar cardioversão. Após estabilização hemodinâmica e correção da acidose metabólica, foi realizada anastomose da VCS (D) com AE (R) com fio de polipropileno $n: 4-0$, em sutura contínua. A heparina foi neutralizada com sulfato de protamina na mesma proporção. Após revisão da hemostasia, o tórax foi fechado por planos anatômicos. O coração (D) ficou localizado no hemitórax esquerdo, logo abaixo do hilo pulmonar e sobre o diafragma. O esquema da técnica cirúrgica está representado na Figura 2.

\section{RESULTADOS}

Em 9 dos 14 cães operados, a recuperação do coração (D) foi espontânea em 4 e houve necessidade de cardioversão em 4 . Em 5 cães, não foi possível completar a experiência por: sangramento nas anastomoses das aortas em 3 cães, distensão do coração do cão (D) em 1 cão e distúrbio metabólico (hipopotassemia) em outro cão.

Avaliação do eletrocardiograma: o traçado eletrocardiográfico, após a anastomose das aortas, ou seja, quando o coração (D) já recebia fluxo coronário, revelou presença dos batimentos dos dois coraçōes. O rítmo era em fibrilação ventricular (FV), após anastomose, o qual reverteu em batimentos efetivos após cardioversão (Figura 3). Em algumas ocasiōes, o coração voltou a bater espontaneamente, mas entrou em FV (D), sendo necessária cardioversão para a sua recuperação. Nesta, os batimentos antes da FV eram sincrónicos (Figura 4). Em contrapartida, foi observada assincronia dos batimentos do (D) e (R) (Figura 5). 
CARVALHO, R. G.: KRICHENKO A.; GIUBLIN, P.; VARELA. A.; AMORIM, M. J.; BUENO. R. L.; RIBEIRO, E. J.; BROFMAN, P. R.; LOURES, D. R. - Transplante heterotópico do coração sem auxilio da circulaçâo extracórporea: estudo experimental em caes. Rev. Bras. Cir. Cardiovasc., 1(2):49-56, 1986.

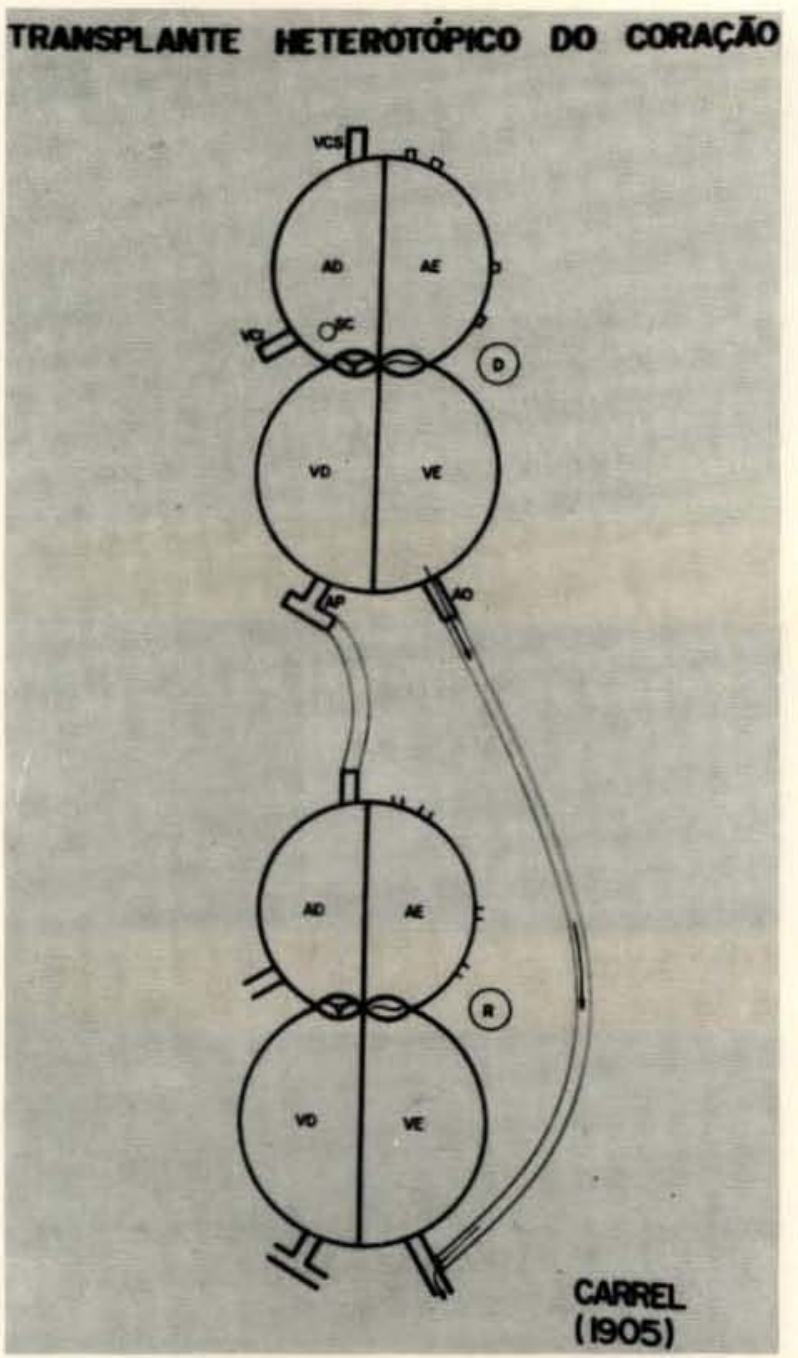

Fig. 1 - Esquema do transplante realizado por Carrel. $\mathrm{R}=$ receptor; $D=$ doador; $A D=$ átrio direito; $V D=$ ventriculo direito; $A P$ = artéria pulmonar: $\mathrm{AE}=$ átrio esquerdo: $\mathrm{VE}=$ ventriculo esquerdo; $\mathrm{Ao}=$ aorta; $\mathrm{SC}=$ seio coronário.

Avaliação da curva de pressão na aorta: durante o estudo hemodinâmico, foi registrada a curva de pressão na aorta ascendente do (R). Foi possível observar duas curvas de pressão (Figura 6), ou somente uma curva, mas apiculada e em sincronismo com o ECG (Figura 7). Durante a FV do coração $(R)$, a pressāo arterial se manteve às custas dos batimentos do coração (D), como está demonstrado na Figura 8.

Avaliação da cineangiocardiografia: a via de acesso para o estudo hemodinâmico foi a artéria femoral direita. O catéter atingiu o coração (D), retrogradamente. Na Figura 9, observa-se ventriculografia esquerda, contrastando até aorta do (R). $\mathrm{Na}$ Figura $9 b, 0$ catéter atingiu o $A D$, retrogradamente, ultrapassando pela $\mathrm{CIA}$ e contrastando a VCS, $A D, A E, V D$ e VE e, na Figura 9c, vêem-se a aorta ascendente do câo (D) e as artérias coroná- rias. Durante a FV do coração $(\mathrm{R})$ e aortografia do cão (D), contrastou retrogradamente a aorta do câo (R), mantendo, assim, o débito cardíaco (Figura 10a).

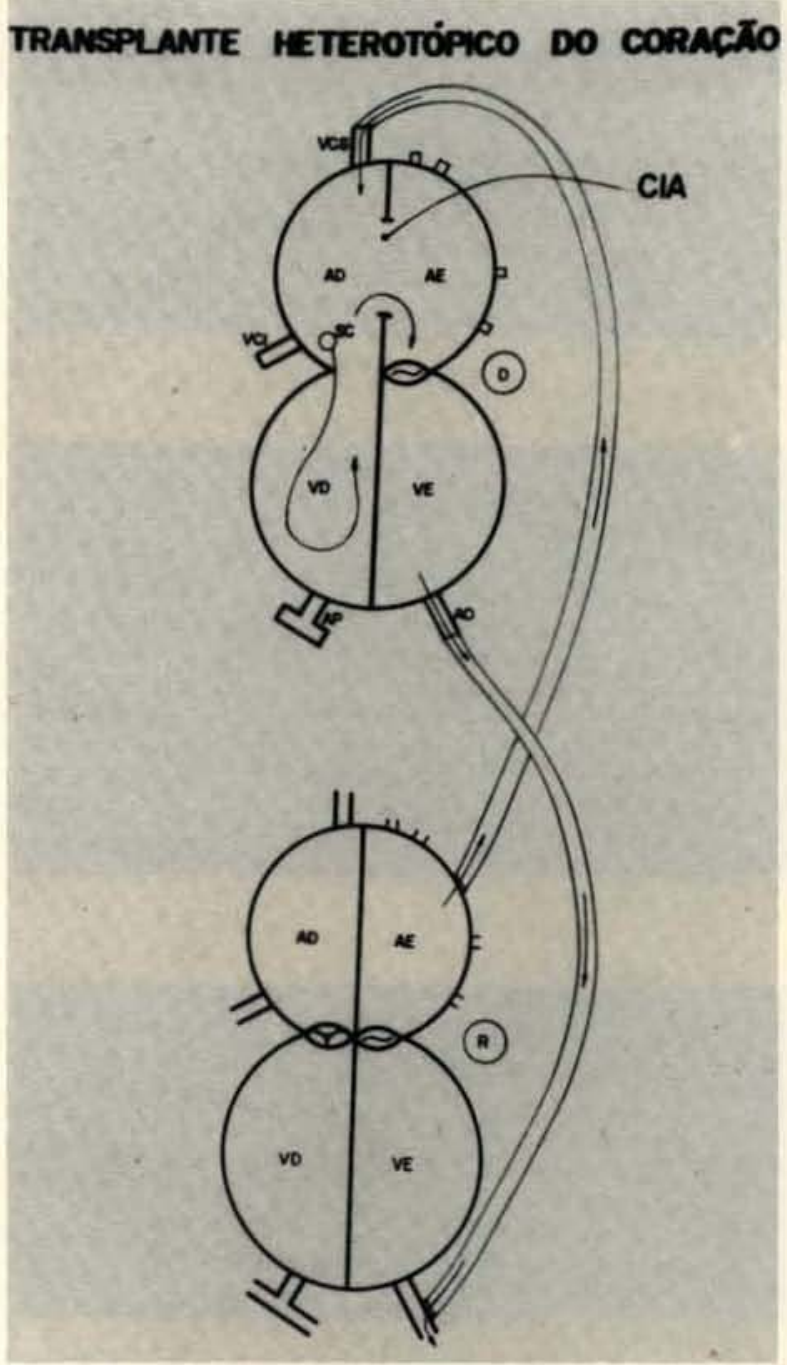

Fig. 2 - Esquerdo do presente trabalho. $\mathrm{CIA}=$ comunicaçâo interatrial; $\mathrm{SC}=$ seio coronário. Demais abreviaturas, vide Fig. 1

\section{DISCUSSĀO}

Desde o início deste século, quando CARREL \& GUTHRIE $^{7}$ realizaram, pela primeira vez, um transplante de órgão, várias técnicas têm sido empregadas $^{10,18}$. O local do implante do coração (D) poderá ser no pescoço $0^{7,}{ }^{16}$, abdômen ${ }^{12,}{ }^{19}$, ou tórax ${ }^{2}$ 4. 10, 15 . Existem alguns inconvenientes da regiāo cervical, como o tamanho do coração (D), que deverá ser pequeno. No abdômen, poderá ocorrer íleo paralítico, obstrução intestinal e até intussuscepção das alças intestinais, como descrevem JAMIESON et alir ${ }^{3}$. Pelos bons resultados e facilidades, opta- 
CARVALHO, R. G.; KRICHENKO A.; GIUBLIN, P.; VARELA, A.; AMORIM, M. J.; BUENO, R. L.; RIBEIRO, E. J.; BROFMAN, P. R.; LOURES, D. R. - Transolante heterotópico do coração sem auxilio da circulação extracórporea: estudo experimental em cāes. Rev. Bras. Cir. Cardiovasc., 1(2):49-56, 1986.

mos por realizá-lo na região torácica, com via de acesso através do 4 : espaço intercostal esquerdo.
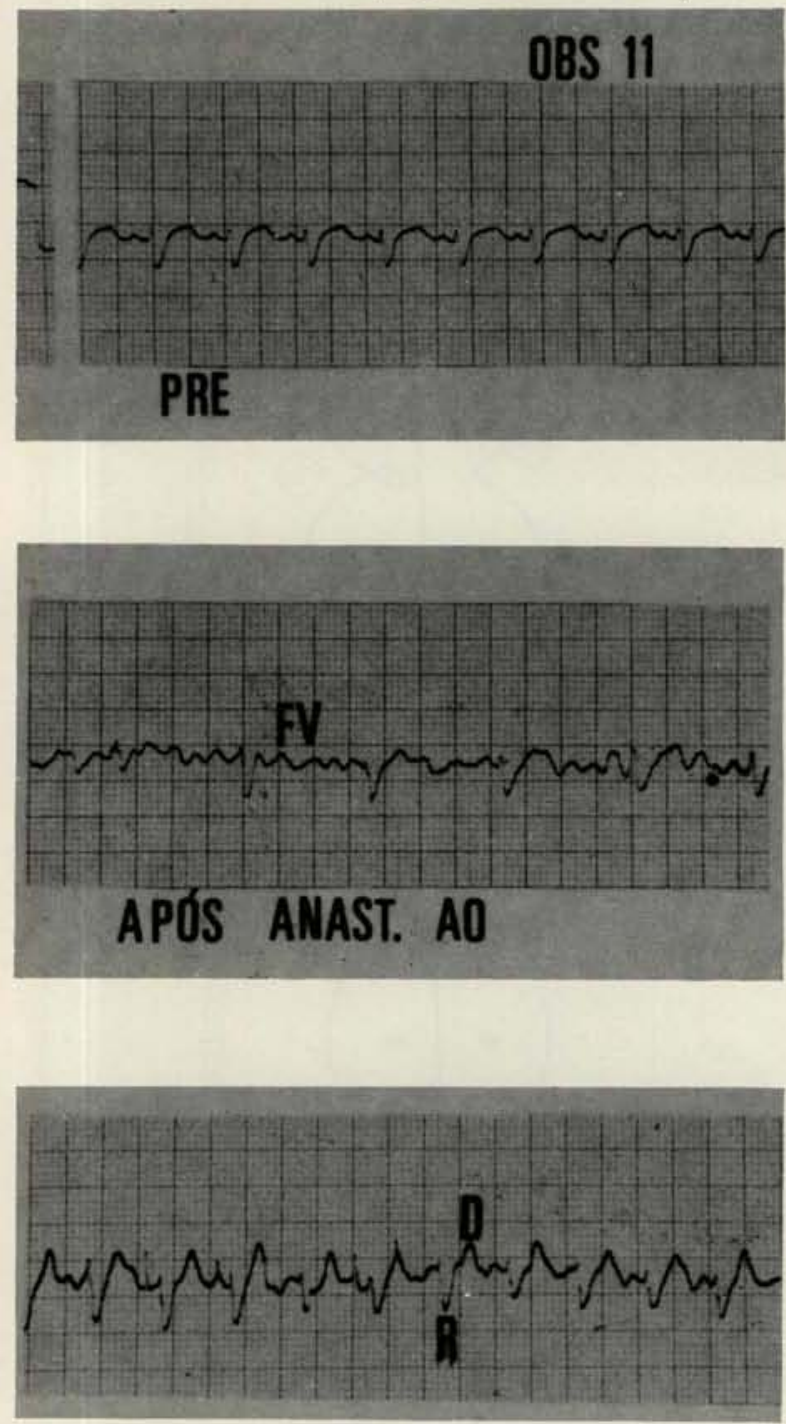

Fig. 3- ECG mostrando ritmo de fibrilaçăo ventricular do coração doador. $\mathrm{PRE}=$ traçado pré-operatório; obs = observaçăo; FV = fibrilação ventricular; anast. $=$ anastomose; $A 0=$ aorta; $\mathrm{D}=$ doador $\mathrm{R}=$ receptor

O transplante heterotópico engloba duas situações distintas. Uma é o transplante em paralelo e outra é a assistência ao coração esquerdo. No coração em paralelo, todas as cavidades dos dois coraçōes estāo em comunicação entre sí. Por exemplo: $A E(D)-A E(R) ; A D(D)-A D(R)$; $A P(D)-A P(R) ; A o(D)-A o(R)$. Este modelo foi inicialmente descrito por McGOUGH et aliit ${ }^{75}$, em 1966. E no coração auxiliar ao ventrículo esquerdo, o princípio é a comunicação entre as duas aortas, com eliminação das anastomoses das cavidades direitas. Nestes casos, o sangue do $\mathrm{AE}(\mathrm{R})$ deverá ser "drenado" para o coração (D).
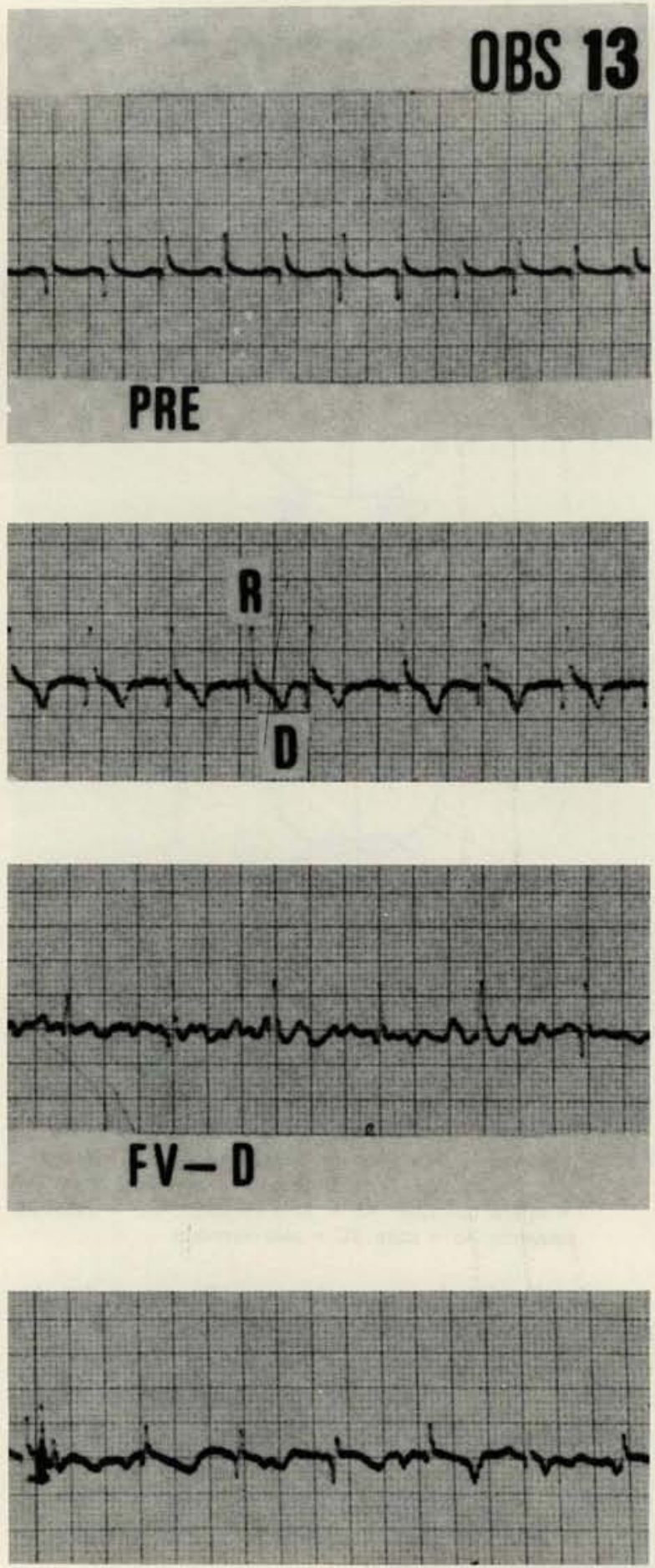

Fig. 4 - ECG revelando sincronismo dos batimentos dos dois coraçōes e ritmo de fibrilaçăo ventricular do coraçăo doador.

A técnica que nós utilizamos foi para a assistência ao ventrículo esquerdo. Conforme o esquema da Figura 2, o sangue do $A E(R)$ atinge o coração (D) através da anastomose do $A E(R)$ com VCS (D). Como o TP (D) está ocluído e não existe 
CARVALHO, R. G.; KRICHENKO A.; GIUBLIN, P.; VARELA, A.; AMORIM, M. J.; BUENO, R. L.; RIBEIRO, E. J.; BROFMAN, P. R.; LOURES, D. R. - Transplante heterotópico do coração sem auxilio da circulação extracórporea: estudo experimental em cães. Rev. Bras. Cir. Cardiovasc., 1(2):49-56, 1986.

valva tricúspide, o sangue se dirige para o $A E(D)$ através de ampla CIA e, então, irá auxiliar o VE (R) pela anastomose das duas aortas. O sangue do seio coronário drenará para o $\mathrm{AE}(\mathrm{D})$, através da CIA. Com a presença desta, eliminamos anastomose entre TP (D) e AE (D), como descreveram BARBERO-MARCIAL et alii?. Na técnica por nós empregada, utilizamos apenas duas anastomoses vasculares, sendo que, durante uma anastomose, o coração (D) permanece parado. STANSEL Jr. \& TERINO ${ }^{19}$ empregaram técnica semelhante, mas apenas com o a realização de uma anastomose (aortas). Este método apresentou algumas complicações, como: embolia aérea, trombose e, principalmente, distensão do coração direito. Por estes motivos, no tempo entre as anastomoses das aortas e da VCS (D) com AE (R), nós drenamos o sangue do $A E(D)$ para a veia femoral do $(R)$, para evitar distenção do VD (D).

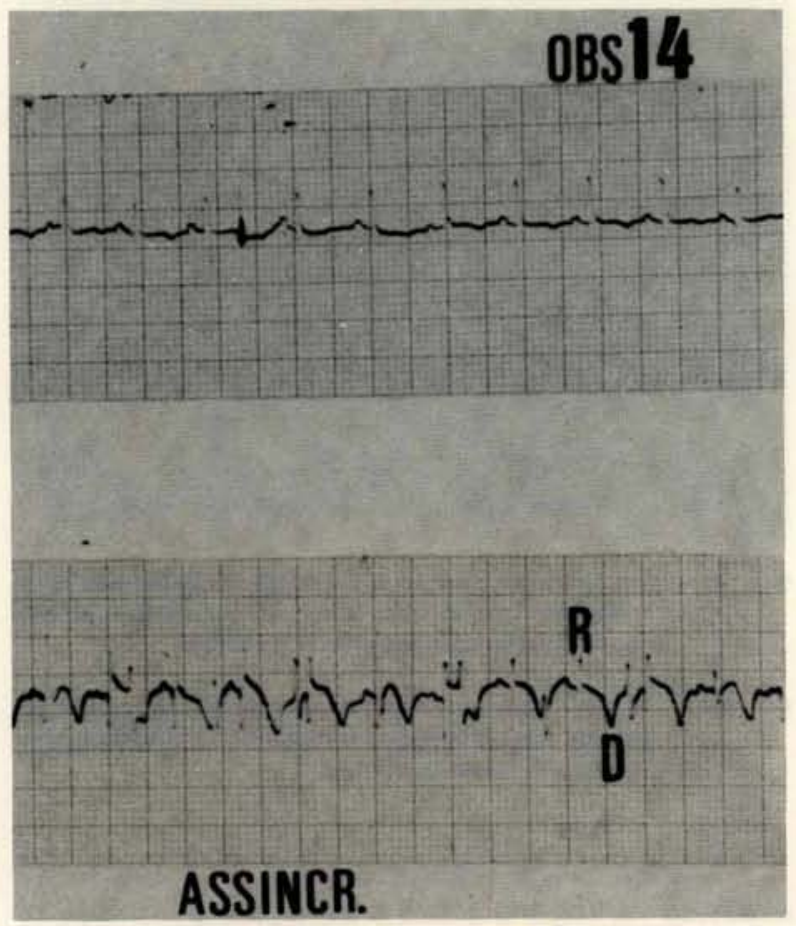

Fig. 5-ECG em que mostra batimentos assincrónicos. Assincr. = assincronia.

Após as experiências realizadas por CARREL \& GUTHRIE $^{7}$ e por MANN et alii ${ }^{16}$, o coração bateu por uma hora e 24 horas, respectivamente. Normalmente, as técnicas de TH têm a finalidade de avaliar dados eletrocardiográficos, patológicos e de rejeição. Raramente são realizados estudos hemodinâmicos para comprovar a efetividade do método. SCHAFF et alii ${ }^{18}$, empregando técnica semelhante, comprovou a eficácia da operação apenas com traçados gráficos de pressão, débito cardíaco, etc. Em nosso estudo, além de demonstrar os batimen- tos de ambos os coraçōes pelo ECG, realizamos cateterismo cardiaco. Neste procedimento, ficou evidente o auxílio dado ao ventrículo esquerdo, como, por exemplo, em uma observação onde o coração (R) entrou em fibrilação ventricular e o débito cardíaco se manteve às custas do coração (D) (Figura 10a).

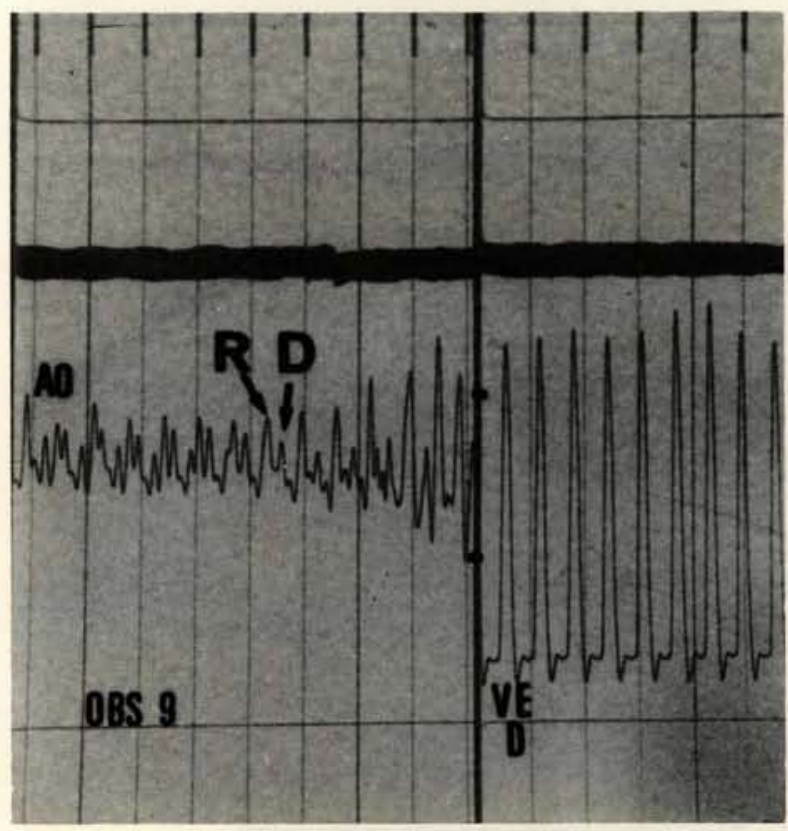

Fig. 6 - Curva de pressão em aorta ascendente, mostrando dois picos.

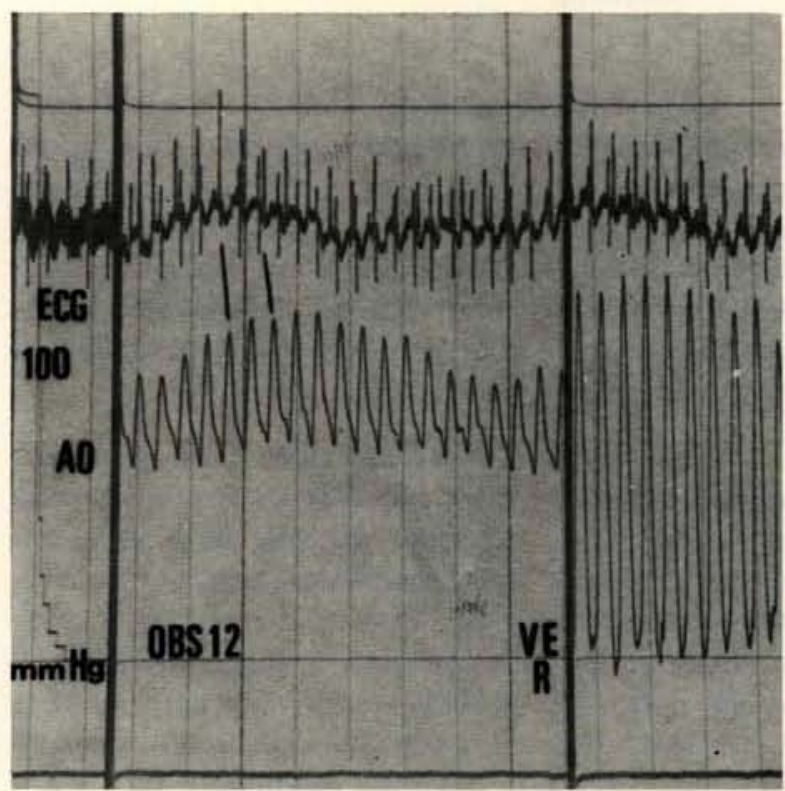

Fig. 7 - Curva de pressão mostrando um pico em sincronismo com o ECG. 
CARVAlho, R. G.; KRICHENKo A.; GIUBlin, P.: VARELA, A.; AMORIM, M. J.; BUeno, R. L.; RiBeiRo, E. J.; BROFMAN. P. R.; LOURES, D. R. - Transplante heterotópico do coraçāo sem auxilio da circulação extracórporea: estudo experimental em cães. Rev. Bras. Cir. Cardiovasc., 1(2):49-56, 1986.

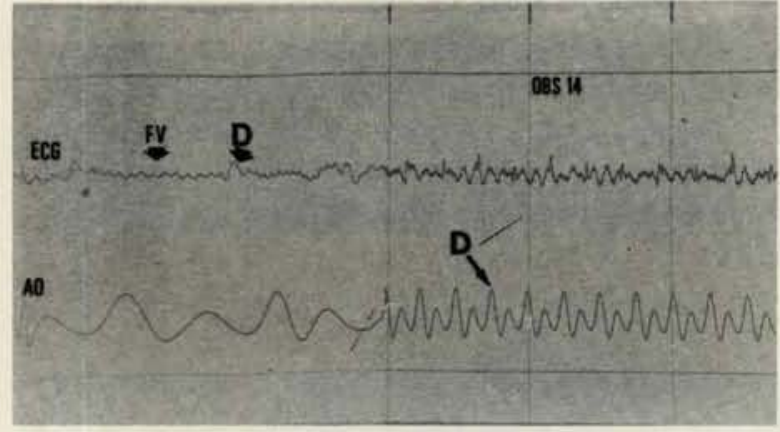

Fig. 8-Curva de pressão em aorta, demonstrado a manutençăo da pressăo arterial durante fibrilaçăo ventricular do cão receptor.

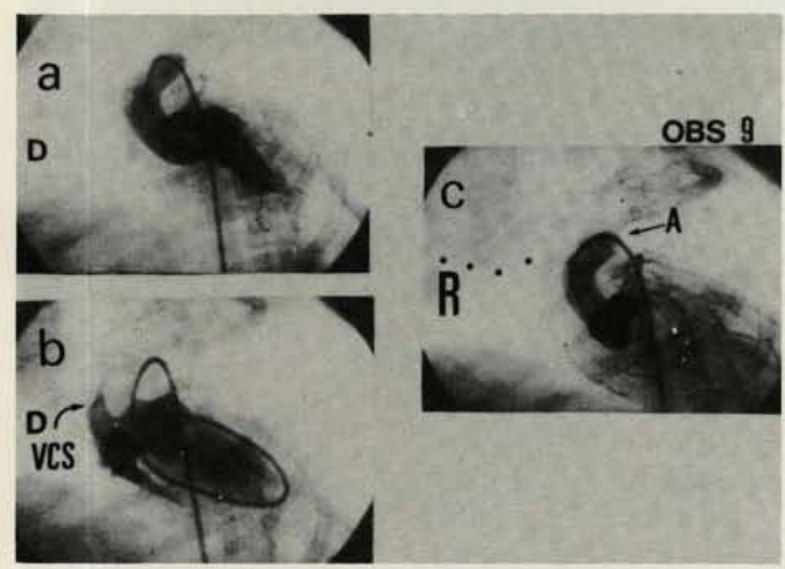

Fig. $9 \mathrm{a}-$ Ventriculografia esquerda do cão doador.

Fig. $9 \mathrm{~b}-\mathrm{O}$ catéter atingiu o átrio direito, retrogradamente, através da CIA. VCS = veia cava superior.

Fig. $9 \mathrm{c}$ - Aortografia do coração doador. $A=$ local de anastomose das aortas. Asteriscos = delimitação da área cardíaca do coraçăo (R).

Uma das dificuldades relatadas na literatura é a de realização da biópsia, quando o transplante é heterotópico ${ }^{10},{ }^{13},{ }^{18}$. Mas, em nossa casuística, isto não ocorreu. Foi fácil a sua realização. Para tal, um de nós (A. K.) adaptou um biótomo - catéter, que alcança o VE (D) por cateterismo retrógrado do cão receptor. Assim, pode ser feita biópsia direta do VE (Figura 10b).

As principais indicações para o TH são: miocardiopatias causadas por doença arterial coronária, miocardite, doenças valvares de grau avançado, insucesso em transplantes anteriores e, até, endomiocardiofibrose ${ }^{8}$. Porém, o mais importante é saber quando não se deve realizar, tanto o $\mathrm{TH}$, como o TO. BARNARD et alii ${ }^{4}$ contrainaicam um transplante quando existe infecção atıva, doença hepática severa e diabetes avançada. COOPER et alii ${ }^{8}$, além das contraindicaçōes já citadas, complementam: infecção grave de outro órgão, doença vascular periférica, infarto pulmonar recente, doença mental e personalidade difícil para o pós-operatório.
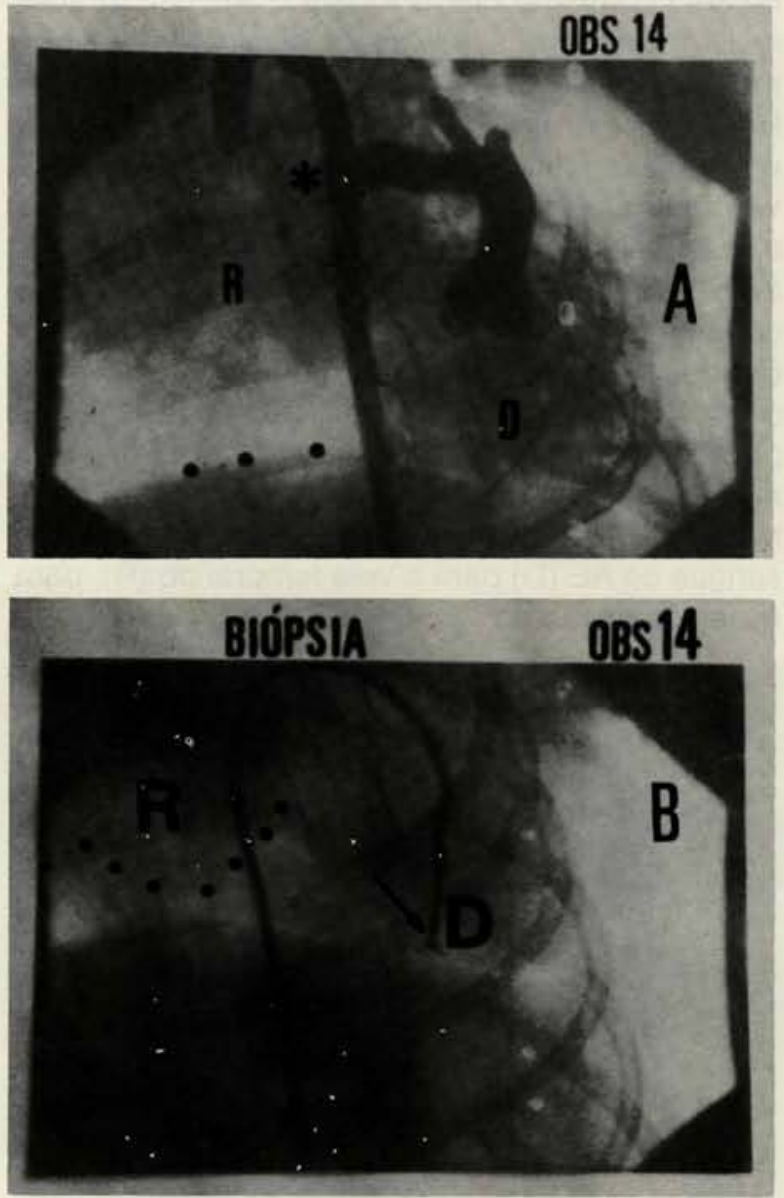

Fig. 10a - Aortografia do coração (D), durante fibrilaçăo ventricular do coraçăo $(R)$. Asterisco maior $=$ nivel de anastomose das aortas; asteriscos menores = diafragma.

Fig. $10 \mathrm{~b}$ - Catéter - biótomo em VE do coraçăo (D). Asteriscos = delimitam área cardiaca do coraçăo (R). Explicaçōes, vide texto. Seta $=$ ponta do biótomo.

O transplante heterotópico ${ }^{3,5,6,13}$ apresenta algumas vantagens sobre o transplante ortotópico. BARNARD ${ }^{3}$ comenta como vantagens: a permanência do coração do receptor; o auxilio ao coração (R) pode ser permanente, ou temporário, e pode ser realizado em pacientes com hipertensão pulmonar. Em outras publicações ${ }^{5}, 6,{ }^{13}$, o grupo da África do Sul descreve o manuseio mais fácil da rejeição, no TH.

O tratamento poderá ser mais prolongado e menos agressivo, tendo em vista que o débito cardíaco poderá ser mantido pelos batimentos, ou do coração (R), ou do (D). Inclusive, está descrito um caso em que houve rejeição do coração (D), permanecendo em fibrilação ventricular por 33 dias, com 
CARVALHO, R. G.; KRICHENKO A.; GIUBLIN, P.; VARELA, A.; AMORIM, M. J.; BUENO, R. L.; RIBEIRO, E. J.; BROFMAN, P. R.; LOURES, D. R. - Transplante heterotópico do coração sem auxilio da circulação extracórporea: estudo experimental em cảes. Rev. Bras. Cir. Cardiovasc., 1(2):49-56, 1986

boa recuperação após o tratamento ${ }^{5}$. Outra vantagem é a proporção do tamanho dos coraçōes. MELVIN et alii ${ }^{17}$ relatam o caso de uma paciente de 24 anos com miocardite pós gastroenterite, que recebeu o coração de uma criança de 12 anos, com boa evolução. Algumas desvantagens ocorrem no TH. A presença de um coração dilatado (R) favorece a formação de trombos no VE ou VD; o baixo débito leva a uma diminuição do fluxo, favorecendo a presença de endocardite infecciosa, sendo pior em portadores de próteses valvulares ${ }^{14}$.
Pélo exposto, concluímos que: 1) esta técnica dispensa o uso da circulação extracorpórea; 2) são realizadas apenas duas anastomoses vasculares; 3) a proteção miocárdica, através da solução cardioplégica cristalóide, poderá ter contribuído para os bons resultados conseguidos; 4) a biópsia do VE foi fácil de ser realizada pelo catéter-biótomo; 5) houve boa resposta hemodinâmica do coração auxiliar; 6) eventualmente, este procedimento poderá ser aplicado na clínica.

CARVALHO, R. G.; KRICHENKO, A.; GIUBLIN, P.; VARELA, A.; AMORIM, M. J.; BUENO, R. L.; RIBEIRO, E. J.; BROFMAN, P. R.; LOURES, D. R. - Heterotopic heart transplant without extra-corporeal circulation: an experimental study in dogs. Rev. Bras. Cir. Cardiovasc., 1 (2):49-56, 1986.

ABSTRACT: The authors describe a new heterotopic heart transplantation technique. Fourteen adult mongrel dogs were operated on via left lateral thoracotomy. Only two vascular anastomosis were performed, without extra-corporeal circulation. The dogs tolerated well the procedure. Cardiac catheterization demonstrated the method to be efficient. There is the possibility of applying this technique in humans.

DESCRIPTORS: heart transplant, heterotopic, experimental.

\section{REFERÊNCIAS BIBLIOGRÁFICAS}

1 ALIVIZATOS, P. A.; GUERRATY, A. J.; LOWER, R. R. - Circulatory assistance with a cardiac allograft after exclusion of the canine left ventficle. Ann. Thorac. Surg., 34 (2): 132-137, 1982.

2 BARBERO-MARCIAL, M.; ARMELIN, E.; STOLF, N. A. G.; SILVA, S. S.; LEMOS, P. C. P.; AUN, F.; PEREIRA, S. N.; ARIE, S.; GALEANO, N.; MARQUES, E.; VERGINELLI, G.; BITTENCOURT, D.; MACRUZ, R.; DÉCOURT, L. V.; ZERBINI, E. J. - Circulaçāo assistida com transplante de coração auxiliar: cirurgia e hemodinâmica; estudo experimental. Arq. Bras. Cardiol., 24 (Supl. 1): 5-24, 1971.

3 BARNARD, C. N. - Heterotopic versus orthotopic heart transplantation. Transplant. Proc., 8 (1): 15-19, 1976.

4 BARNARD, C. N.; BARNARD, M. S.; COOPER, D. K. C.; CURCHIO, C. A.; HASSOULAS, J.; NOVITSKY, D.; WOLPOWITZ, A. - The present status of heterotopic cardiac transplantation. J. Thorac. Cardiovasc. Surg., 81 (3): 433-439, 1981.

5 BARNARD, C. N.; LOSMAN, J. G.; CURCIO, C. A.; SANCHEZ, H. E.; WOLPOWITZ, A.; BARNARD, M. S. The advantage of heterotopic cardiac transplantation over orthotopic cardiac transplantation in the management of severe acute rejection. J. Thorac. Cardiovasc. Surg., 74 (6): 918-924, 1977.

6 BARNARD, C. N. \& WOLPOWITZ, A. - Heterotopic versus orthotopic heart transplantation. Transplant. Proc., 11 (1): 309-312, 1979.
7 CARREL, A. \& GUTHRIS, C. C. - The transplantation of veins and organs. Am. Med., 11: 1101, 1905.

8 COOPER, D. K. C.; CHARLES, R. G.; BECK, W.; BARNARD, C. N. - The assessment and selection of patients for heterotopic heart transplantation. $S$. Afr. Med. J., 61 (16): 575-578, 1982.

9 GRIEPP, R. B.; STINSON, E. B.; BIEBER, C. P.; REITZ, B. A.; COPELAND, J. G.; OYER, P. E.; SHUMWAY, N. E. - Human heart transplantation: current status. Ann. Thorac. Surg., 22 (2): 171-175, 1976.

10 JAMIESON, S. W.; BURTON, N. A.; REITZ, B. A.; SHUMWAY, N. E. - A new method for heterotopic cardiac transplantation in the dog. J. Surg. Res., 32 (2): 150-153, 1982.

11 JARA, F. M.; TOLEDO-PEREYRA, L. H.; LEWIS Jr., J. W.; MAGILLIGAN Jr., D. J. - Auxiliary heart transplantation. Ann. Thorac. Surg., 29 (5): 483-488, 1980.

12 LEE, S.; MACEDO, A. R.; CURTIS, G. P.; LEE, D.; ORLOFF, M. J. - - A simplified model for heterotopic rat heart transplantation. Transplantation, 33 (4): 438-442, 1982.

13 LOSMAN, J. G. \& BARNARD, C. N. - Heterotopic heart transplantation; a valid alternative to orthotopic transplantation: results, advantages, and disadvantages. J. Surg. Res., 32 (4): 297-312, 1982. 
CARVALHO, R. G.; KRICHENKO A.; GIUBLIN, P.; VARELA, A.; AMORIM, M. J.; BUENO, R. L.; RIBEIRO, E. J.; BROFMAN, P. R.: LOURES, D. R. - Transplante heterotópico do coraçaao sem auxilio da circulaçăo extracórporea: estudo experimental em cảes. Rev. Bras. Cir. Cardiovasc. 1(2):49-56, 1986.

LOSMAN, J. G.; LEVINE, H.; CAMPBELL, C. D.; REPLOGLE, R. L.; HASSOULAS, T.; NOVITSKY, D.; COOPER, D. K. C.; BARNARD, C. N. - Changes in indications for heart transplantation: an additional argument for the preservation of the recipient's own heart. $J$, Thorac. Cardiovasc. Surg., 84 (5): 716-726, 1982.

15 McGOUGH, E. C.; BREWER, P. L.; REEMTSMA, K. The parallel heart: studies of intrathoracic auxiliary cardiac transplants. Surgery, 60 (1): 153-158, 1966.

MANN, F. C.; PRIESTLEY, J. T.; MARKOWITZ, J.; YATER, W. M. - Transplantation of the intact mammalian heart. Arch. Surg., 26 (1): 219-224, 1933.

17 MELVIN, K. R.; POLLICK, C.; HUNT, S. A.; MCDOUGALL, R.; GORIS, M. L.; OYER, P.; POPP, R. L.; STINSON, E. B. - Cardiovascular physiology in a case of heterotopic cardiac transplantation. Am. J. Cardiol., 49 (5): 1301-1308, 1982.

SCHAFF, H. V.; TAGO, M.; GERSH, B. J.; PLUTH, J. R.; FETTER, J.: KAYE, M. P. - Simplified method of heterotopic cardiac transplantation for left ventricular assist. J. Thorac. Cardiovasc. Surg., 85 (3): 434-439, 1983.

19 STANSEL Jr., H. C. \& TERINO, E. O. - A singleanastomosis heterotopic cardiac homotransplant. Arch. Surg., 90 (1): 444-448, 1965.

20 TAKAOKA, K. - Respirador automático de Takaoka. Rev. Bras. Anest., 14 (4): 380-399, 1964.

\section{Discussão}

DR. IVO A. NESRALLA

Porto Alegre, RS

O trabalho do Dr. Roberto G. Carvalho, pela originalidade e simplicidade técnica, espelha a alta qualidade científica do grupo cirúrgico do Hospital Evangélico, de Curitiba.

Gostaríamos de tecer dois comentários, ambos inerentes ao item 4: aplicabilidade clínica deste procedimento.
10) Tentamos realizar a presente técnica em cadáver. Pareceu-nos que o fato de serem necessários longos pedículos vasculares, tanto de veia cava superior, como de aorta, para efetuar as anastomoses propostas, o coração permanece pouco fixado sobre o diafragma (diapositivo), e pode sofrer torçōes e traçōes. Perguntamos se isto não poderia torcer o eixo cardíaco, com perda da função hemodinâmica do coração transplantado.

2.) No caso de assistência ventricular esquerda prolongada, a realização das biópsias endomiocárdicas ficam prejudicadas, pelo difícil acesso às cavidades cardiacas. Gostaríamos de ouvir o colega, na solução destes equacionamentos.

\section{DR. GOMES DE CARVALHO (Encerrando)}

Gostaria de agradecer os elogios e comentários da parte do Dr. Ivo Nesralla. Em relação à dúvida sobre a possivel torção da aorta do coração do cão doador, isto aconteceu na segunda observação. Para evitar tal fato, nós seccionamos a aorta do doador no sentido oblíquo. Desta maneira, existe maior área de contato no local da anastomose, evitando esta complicaçāo. Nāo houve dificuldade de se realizar a biópsia, tendo em vista que nós temos disponível um biótomo-catéter, facilitando a realização da biópsia. Finalizando, acho que este trabalho nos mostra que é possivel de se realizar um transplante heterotópico. Desta maneira, fica bastante simples, tendo em vista que utilizamos apenas duas anastomoses e sem o uso da circulação extracorpórea. 